interact in complex and subtle ways. For example, we inevitably used implicit standards in making observations; the very act of observation seemed to improve practice; and agreed standards were tempered by the feasibility of improvements.

Another lesson is that a great deal of work is needed to run and evaluate such an audit, not only to perform the audit itself but to arrange and service the meetings; select random notes and distribute them with the questionnaires; chase the responses, enter the results on to computer and analyse them; develop and distribute the guidelines and standards; ensure that suggestions for improved practices are followed through; and, above all, to maintain momentum and combat flagging morale when the auditors and audited alike begin to wonder whether it is all worth while. After a year of working our way around the audit cycle, however, we are convinced of its value. We have come a long way, and we gladly accept the need to go much further.

We thank Ms Jane Wadsworth for statistical advice, Ms Jackie Glossop for her invaluable administrative efforts, and the other members of the steering committee including Drs D
Bell, C Cayley, M Dancy, H Davies, D Loft, S McHardyYoung, F Mathey, G Misiewicz, S Roach, P Sharp, and D Wood.

I Royal College of Physicians. Medical audit-a first report: what, why and how. London: RCP, 1989.

2 Secretaries of State for Health, Wales, Northern Ireland, and Scotland. Medical audit. Working paper 6. London: HMSO, 1989.

Shaw $\mathrm{CD}$. Aspects of audit-2. Audit in British hospitals. Br Med $1980: 290: 1314-6$

4 Shaw CD. Aspects of audit-4. Acceptability of audit. Br Med $\mathcal{f} 1980 ; 290$ : $443-5$.

5 Heath DA. Medical audit in general medicine. $\mathcal{J} R$ Coll Physicians Lond 1981;15:197-9.

6 Heath DA, Hoffenberg R, Bishop JM, et al. Medical audits. $f R$ Coll Physicians Lond 1980;14:200-1.

7 van't Hoff W. Medical audit. Midlands Medicine, The Fournal of the North Staffordshire Medical Institute, 1986;17:28-30.

8 van't Hoff W. Audit reviewed. A progress report. $\mathcal{I} R$ Coll Physicians Lond 1982;16:62-4.

9 Swansea Physicians Audit Group. Implementing audit in a division of medicine. $\mathcal{F}$ R Coll Physicians Lond 1982;16:252-4.

10 Bennett J, Shaw CD. Guidance on what should be in the clinical medical records for the Brighton Health Authority. Medical Record and Health Care Information fournal 1987;28:103-10.

11 Stevens G, Bennett J. Clinical audit-occurrence screening for quality assurance. Health Services Management 1989;85:178-81.

12 Shaw CD. Criterion based audit. BrMed f 1990;300:649-51.

13 Bennett J, Walshe K. Occurrence screening as a method of audit. Br Med $\mathcal{F}$ 1990;300:1248-51.

(Accepted 31 May 1990)

\title{
How easy is it to contact the duty medical doctor responsible for acute admissions?
}

\author{
Ameet Bakhai, Frances Goodman, Henryk Juchniewichz, Andrew Martin, Graham Porter, \\ Craig White, Laurence Williams, Anthony Hopkins
}

\section{Abstract}

Objective-To ascertain ease or difficulty of contacting duty junior doctors responsible for acute medical admissions by telephone.

Design-Telephone survey of hospitals in six health regions in England and Wales.

Setting-70 Randomly selected hospitals, 15 of which were excluded because of non-acceptance of acute medical admissions.

Participants - 71 Duty doctors (duty house physicians, senior house officers, or registrars responsible for acute medical admissions) in $\mathbf{4 8}$ hospitals; seven duty doctors in seven hospitals were excluded (four declined to participate and three required a written explanation of the survey). 67 Doctors gave full information to all questions.

Main outcome measures-Time taken for hospital switchboards and duty doctors to reply to telephone call, diagnoses of patients recently admitted, and on call rotas and hours of sleep of duty doctors.

Results-Hospital switchboards responded within 30 seconds in $87(74 \%)$ calls, and in 76 calls $(64 \%)$ the duty doctor requested was contacted within a further two minutes. Chest pain, possibly due to myocardial infarction, was the most common reason for acute medical admissions. Nearly half $(48 \%)$ of the duty doctors in larger hospitals reported having 4.5 hours sleep or less on their nights on call. Most (30) were on a one in three rota; two were on a one in two rota.

Conclusions-Despite impressions to the contrary contacting the duty medical team by telephone seemed fairly easy. Although most junior doctors were on a rota of one in three or better, insufficient recognition may be given to their deprivation of sleep during nights on duty.

\section{Introduction}

Family doctors attempting to arrange the admission of a patient with a medical illness as an acute admission often state that it is difficult to contact the admitting house physician, senior house officer, or registrar responsible for receiving the patient and allocating a bed. We decided to find out just how difficult this was, by means of a telephone survey. We also obtained information about the numbers of acute medical admissions and the associated diagnoses and inquired about the duty rota of the admitting doctors and the amount of sleep they had had in the previous 24 hours.

\section{Methods}

Six of the NHS regions in England and Wales were chosen at random (North West Thames, South East Thames, Trent, West Midlands, North Western, and South Western). According to the Medical Directory, hospitals within each region were graded as large and small hospitals with reference to the median number of beds within each region. From this list 35 large hospitals and 35 small hospitals were chosen randomly. Fifteen hospitals were then excluded as they had never accepted or no longer accepted acute medical admissions. Telephone calls were made by the student authors to the remaining 55 hospitals over two weeks.

The interval between the first set of ringing tones and the time taken for the hospital switchboard to reply and the interval between requesting the switchboard operator to connect the caller with the duty house physician, senior house officer, or registrar responsible for acute medical admissions (the duty doctor) were recorded. When the duty doctors answered, the callers briefly explained the inquiry and requested them to record the age, sex, and provisional diagnosis of all patients admitted during their current 24 hour on call period and of those who could not be admitted, even though duty doctors thought that admission would have been advisable. The callers also explained their interest in how undisturbed was the duty doctors' sleep during the night on duty and sought information about 


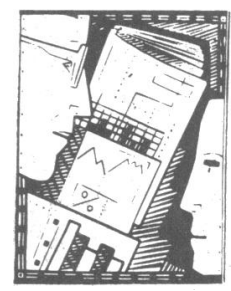

their rotas. All calls were made between 0900 and 1100 . In general, an explanation of the requirements of the study could be given in under five minutes, and collecting the data the following day again took less than five minutes.

\section{Results}

Four duty doctors stated that they were too busy to collaborate, and a further three wanted a written explanation of the background to the survey, which, in the timescale of a project of only three weeks, could not be provided. In the remaining 48 hospitals information was obtained from 71 duty doctors on call, as sometimes hospitals had more than one duty doctor-for example, in coronary care or geriatric medicine, in addition to general medicine. All but four of these 71 doctors gave full information about their admissions, hours of sleep, and duty rotas.

Table I shows the time distribution between the first ringing tone and reply by the hospital switchboard for 118 initial and return calls. Most hospital switchboards answered promptly; 87 (74\%) of all calls were answered within 30 seconds and only $10(8 \%)$ after longer than 1.5 minutes. Table II shows the distribution of intervals between requesting the switchboard operator

TABLE I-Time taken for hospital switchboard to answer call in six health regions in England and Wales. Figures are numbers of calls

\begin{tabular}{lcccc}
\hline Time (s) & $0-30$ & $31-60$ & $61-90$ & $\geqslant 90$ \\
\hline Small hospitals $(n=20)$ & 40 & 4 & 6 & 4 \\
Large hospitals $(n=28)$ & 47 & 7 & 4 & 6 \\
\hline
\end{tabular}

TABLE II -Time taken for duty doctor to reply to call. Figures are numbers of calls

\begin{tabular}{lcccccc}
\hline Time (s) & $0-60$ & $61-120$ & $121-180$ & $181-240$ & $241-300$ & $>300$ \\
\hline Small hospitals $(\mathrm{n}=20)$ & 18 & 14 & 8 & 3 & 3 & \\
Large hospitals $(\mathrm{n}=28)^{\star}$ & 18 & 26 & 10 & 4 & 2 & $5^{\star}$ \\
\hline
\end{tabular}

*Seven additional calls abandoned after 12 minutes.

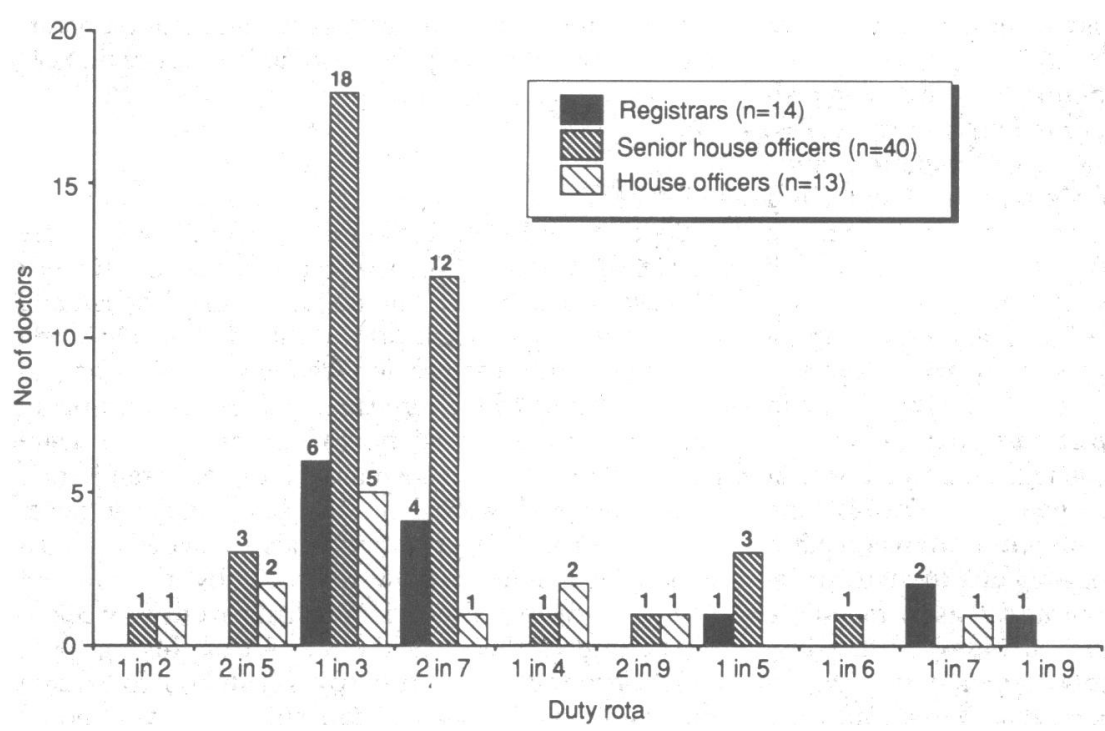

Duty rotas for 67 doctors

TABLE III -Most common diagnosis on admission reported by duty doctors in survey. Numbers of patients in parentheses

\begin{tabular}{|c|c|c|c|c|c|c|c|}
\hline \multirow[b]{2}{*}{ Region } & \multirow{2}{*}{$\begin{array}{l}\text { Total No of } \\
\text { admissions } \\
\text { recorded }\end{array}$} & \multirow{2}{*}{$\begin{array}{c}\text { No of } \\
\text { hospitals }\end{array}$} & \multicolumn{5}{|c|}{ Diagnosis } \\
\hline & & & 1st & 2nd & $3 r d$ & th & 5 th \\
\hline North Western & 120 & 11 & Chest pain, ?myocardial infarction (30) & Chest infection (11) & Cerebrovascular accident $(9)$ & Asthma (9) & Overdose $(8)$ \\
\hline South Western & 50 & 6 & Chest pain, ?myocardial infarction (12) & Cerebrovascular accident $(6)$ & Overdose $(5)$ & Chronic airways limitation (4) & Gastrointestinal bleed (4) \\
\hline West Midlands & 70 & 9 & Chest pain, ?myocardial infarction (18) & Heart failure $(9)$ & Cerebrovascular accident (5) & Chronic arways limitation (3) & Meningism (3) \\
\hline South East Thames & 40 & 4 & Chest pain, ?myocardial infarction $(15)$ & Pneumonia $(7)$ & Asthma (6) & Chronic airways limitation (5) & Cerebrovascular accident (3) \\
\hline North West Thames & 68 & 8 & Chest pain, ?myocardial infarction $(10)$ & Overdose (4) & Cerebrovascular accident (3) & Epigastric pain (3) & Asthma (3) \\
\hline Trent & 88 & 10 & Chest pain, ?myocardial infarction (19) & Heart failure (13) & Overdose $(9)$ & Chronic airways limitation (4) & Deep vein thrombosis (3) \\
\hline Total & 436 & 48 & 104 & & & & \\
\hline
\end{tabular}

to contact the duty doctor and making contact with him or her. Most duty doctors requested were contacted within a reasonable time $-75(64 \%)$ within a further two minutes. Five doctors took more than five minutes to contact, and in a further seven (6\%) the call was abandoned after 12 minutes. Sometimes the delay seemed to be because the switchboard had set about paging the wrong doctor. Of the 43 duty doctors in large hospitals who responded to the inquiry about sleep, $21(49 \%)$ reported spending $4 \cdot 5$ hours or fewer in bed and many remarked that this short period had been interrupted, whereas seven (29\%) of the 24 in smaller hospitals reported 4.5 hours' sleep or less. The figure shows the distribution of rotas of the duty doctors; only two out of the 67 respondents were working in a one in two (illegal) rota. ${ }^{1}$ Table III shows the distribution of provisional diagnoses in patients on admission in the different regions. The duty doctors reported that they could not admit six patients whom they thought should have been admitted.

\section{Discussion}

At the outset of the study we were conscious that the calls would intrude into the doctors' working day, but bearing in mind the triviality of many of the interruptions they face we thought that our survey was justified. Duty doctors were contacted in a surprisingly short time, bearing in mind that some of them may have been performing a procedure or talking to or examining patients. It seems to be human to remember occasional delays, forgetting the usual reasonable response. Delays in contacting doctors on duty in surgical specialties may, however, be longer than we found as such doctors may often be busy in the operating theatre.

The distribution of diagnoses on admission (table III) showed that chest pain, possibly due to myocardial infarction, was the primary reason for acute medical admission in all health regions. Respiratory problems, variously recorded as chest infection, pneumonia, chronic airways obstruction (presumably with superadded infections), and asthma were prominent, as were stroke, self poisoning, and congestive cardiac failure. Particular attention should be given to such conditions in training medical students and preregistration house physicians.

Our survey did not find that the limited provision of acute beds required that admitting duty doctors turn away patients whom they thought should have been admitted. Admittedly, the survey took place in April, and the pressure on medical beds is greatest in winter months. Only six such patients were recorded by the duty doctors, and the reported diagnoses were unimpressive, such as suspected pneumothorax with a normal chest $x$ ray film and a three month history of lethargy with no abnormalities on examination. A recent audit of patients with chest pain seen in the accident and emergency department of Westminster Hospital, London, however, showed that an appreciable number of patients with chest pain not admitted were considered by a consensus panel subsequently to have warranted admission. ${ }^{2}$ The threshold at which a patient is either admitted or turned away probably 
reflects the availability of beds as well as the provisional diagnosis and severity of illness.

Our survey showed that most admitting medical officers were on a rota of one in three or better. As in the United States, ${ }^{3}$ duty doctors cannot expect much time in bed when on call. We found that duty doctors had a better chance of getting more sleep in smaller hospitals.

We thank all those who responded so courteously to our telephone inquiries. Sir Colin Dollery originally suggested this project. Dr Malcolm Law advised the student authors. The research unit of the Royal College of Physicians is supported by a generous grant from the Wolfson Foundation.

1 Department of Health and Social Security. Circulars PM(82)37, AL(MD)3/83, PM(85)1.

2 Emerson PA, Russell NJ, Wyatt J, et al. An audit of doctors' management of patients with chest pain in the accident and emergency department. $Q \mathcal{F} M e d$ 1989;70:213-20.

3 Lurie N, Rank B, Parenti C, Woolley T, Snoke BA. How do house officers spend their nights? A time study of internal medicine house staff on call. N Engl f Med 1989;320:1673.

(Accepted 31 May 1990

\title{
Audit in Person
}

\section{Variations in hospital admissions and the appropriateness of care: American preoccupations?}

\author{
John P Bunker
}

It is not just the explosion in costs that has catalysed preoccupation with the cost effectiveness of medical care in the United States. There is an equally important and growing recognition of the uncertain effectiveness of much of medical care itself, which has emerged directly from the now widely confirmed large and unexplained variations in rates of hospital admissions observed across local, regional, and national populations. Recognition that different segments of the population may receive appreciably different rates of a particular treatment is not new. Glover reported to the Royal College of Physicians in 1938 that rates of tonsillectomy varied as much as 20 -fold among school districts in England and Wales. ${ }^{.}$Threefold and fourfold

\section{... the scientific basis of the practice of medicine is inadequate.}

differences in rates for other surgical procedures were observed in Liverpool, New England, and Uppsala by Pearson et al in $1968^{2}$ and among 11 health planning regions in Kansas by Lewis in 1969.

\section{Magnitude of variation}

I first became aware that there was a large public health problem a year later, when national data on operation rates in the United States became available and I could compare them with those published by the British Hospital In-Patient Enquiry. ${ }^{4}$ People in the United States at that time were twice as likely to undergo surgery as were those in Britain. Whether those in the United States were receiving too much surgery or those in Britain too little was indeterminable. People in the United States had not gained the benefit of living longer; indeed, life expectancy in Great Britain was slightly greater in 1970 . Perhaps they were gaining an improvement in the quality of life, a goal to which much of medical and surgical care is devoted, but there were no data to determine this. Life expectancy in the United States is now slightly greater than in Britain, probably owing more to differences in smoking and other lifestyle factors than to medical care. It is still not possible to say whether the quality of life of the average person in the United States is better than that of one in Britain. The magnitude of the problem became painfully apparent in 1973 with the publication by Wennberg and Gittelsohn of large variations in rates of operation among thirteen "small areas," roughly equivalent to counties, in Vermont. Vermont is a rural state with a largely homogeneous population and no discernible differences in morbidity to account for possible differences in medical need. Variations of equal magnitude in rates of operation were subsequently widely confirmed in other states and in other countries, including Great Britain. ${ }^{6}$ Variations in hospital admissions for medical diagnoses are even greater in the United States; on the basis of widely reported large variations in general practitioner referrals for consultant care, ${ }^{7}$ I judge that they are equally large in Britain. Coulter et al have now confirmed large variations in general medical admissions. ${ }^{7 \mathrm{a}}$

Large variations in hospital admissions might be considered to have very different meanings in the United States and Great Britain. Variations in the United States might be reasonably assumed to include a good deal of overtreatment, and those in Britain, equally large but occurring at considerably lower absolute levels, to represent a good deal of undertreatment. Though these may be valid judgments, the fact that such variations occur in each country is strong evidence that the quality of medical care given by doctors in both is equally variable and uncertain. In the United States a large effort has been made to find the cause of the observed variations in medical practice. Only a small part of the variation has been attributed to variations in the prevalence of disease or to chance statistical variation. Rates of operation have been shown to vary directly with the number of surgeons and rates of admission with the number of beds available, but these explain only part of the effect. More important is the question of how medical decisions to treat similar conditions may vary so greatly among doctors. It is now widely acknowledged that this must mean that the scientific basis of the practice of medicine is inadequate; that the outcomes of treatment are, as a consequence, uncertain; and that, as a further result, doctors disagree among themselves in choosing treatment. ${ }^{8}$ There is also a growing body of evidence that doctors may not use existing scientific knowledge to full advantage.

\section{Judging appropriateness of indications for} procedures

The need for better data on the outcome of diagnostic and therapeutic technologies has been recognised for 